\title{
Distinct Synaptic and Extrasynaptic NMDA Receptors in Developing Cerebellar Granule Neurons
}

\author{
Gavin Rumbaugh ${ }^{1}$ and Stefano Vicini ${ }^{2}$ \\ Departments of ${ }^{1}$ Pharmacology and ${ }^{2}$ Physiology and Biophysics, Georgetown University School of Medicine, \\ Washington, DC 20007
}

In rat cerebellar granule neurons, $\mathrm{mRNA}$ and protein levels of the NR2A and NR2C subunits of the NMDA receptor increase during the second postnatal week. At this time, mRNA and protein levels of the NR2B subunit begin to fall. To investigate targeting of NMDA receptor subunits, we performed whole-cell recordings from rat cerebellar granule neurons at different times during development and investigated the pharmacological and biophysical properties of mossy fiber-evoked NMDA EPSCs. Isolated NMDA EPSCs from newly formed synapses in the first postnatal week exhibited partial block by the NR2B subunitspecific antagonist (1S,2S)-1-(4-hydroxyphenyl)-2-(4-hydroxy4-phenylpiperidino)-1-propanol (CP 101,606). By the end of the second postnatal week, NMDA EPSCs were virtually unaffected by the NR2B antagonist. In parallel, NMDA EPSC decay times decreased over a similar developmental time course. We compared properties of synaptic NMDA receptors with extrasynap-

NMDA receptors are involved in a variety of processes, such as long-term potentiation, neuronal migration, and synaptogenesis (McBain and Mayer, 1994; Sheetz and Constantine-Paton, 1994). In the cerebellum, NMDA receptors are required for normal motor coordination because lack of these receptors in rats yields a phenotype that is noticeably uncoordinated and taxed during locomotion (Kadotani et al., 1996).

NMDA receptors are composed of the obligatory NR1 subunit and at least one copy of NR2A, NR2B, NR2C, or NR2D (McBain and Mayer, 1994; Dingledine et al., 1999). The presence of specific NR2 subunits determines properties of the receptor, including agonist affinity, magnesium sensitivity, deactivation kinetics, modulation by polyamines, and channel conductance (McBain and Mayer, 1994; Dingledine et al., 1999). For example, recombinant NMDA receptors comprising NR1/NR2A heteromers exhibit fast deactivation, little sensitivity to ifenprodil derivatives, and are not modulated by the polyamine spermine. In contrast, NR1/NR2B receptors decay more slowly, are blocked by ifenprodil derivatives, and are potentiated by micromolar levels of spermine (Monyer et al., 1994; Williams et al., 1994; Mott et al., 1998; Vicini et al., 1998). Moreover, NR1/NR2C or NR1/NR2D heteromers have a smaller unitary single-channel

Received July 21, 1999; revised Aug. 27, 1999; accepted Sept. 28, 1999.

This work was supported by National Institute of Mental Health Grants R01 MH58946 and KO2 MH01680. We are grateful to Dr. Barry Wolfe, Dr. Deirdre O'Leary, and Stacie Grossman for critical reading of this manuscript.

Correspondence should be addressed to Dr. Stefano Vicini, Department of Physiology and Biophysics, Georgetown University School of Medicine, 3900 Reservoir Road, NW, Washington, DC 20007. E-mail: svicin01@gusun. georgetown.edu.

Copyright (C) 1999 Society for Neuroscience $0270-6474 / 99 / 1910603-08 \$ 05.00 / 0$ tic receptors that are present on the cell body with rapid application of glutamate to excised nucleated patches. Deactivation of patch responses accelerated with development and closely resembled evoked NMDA EPSCs in rats of the same age. However, patch responses were highly sensitive to CP 101,606 through the second postnatal week, and sensitivity was seen in some neurons up to the fourth postnatal week. Spermine potentiated peak NMDA patch responses from postnatal days 10-14 rats but had little effect on evoked NMDA EPSCs. Our data suggest selective targeting of a distinct NMDA receptor subtype to synaptic receptor populations in cerebellar granule neurons. Later in development, similar changes occur in the extrasynaptic receptor population.

Key words: glutamate receptor; development; cerebellum; EPSC; spermine; patch clamp

conductance and are less sensitive to block by magnesium (Feldmeyer and Cull-Candy, 1996).

In cerebellar granule neurons, the NR1 subunit is ubiquitously present throughout development. In contrast, the NR2 subunits go through variable expression patterns (Watanabe et al., 1994; Wang et al., 1995). NR2B subunit protein expression begins in late embryonic stages but gradually disappears during the second postnatal week (Wang et al., 1995; Takahashi et al., 1996). In parallel to the drop in NR2B subunit expression during the second postnatal week, the NR2A subunit, which is completely absent at birth, begins to appear (Watanabe et al., 1994; Wang et al., 1995). As development continues, the NR2C subunit also begins to appear (Akazawa et al., 1994) and incorporates itself into both synaptic and extrasynaptic NMDA receptors as observed in a NR2A subunit gene knock-out study (Takahashi et al., 1996). In cerebellar granule neurons, synaptic receptors are restricted to the glomerulus and are therefore separated from extrasynaptic receptors in the cell body (Palay and Chan-Palay, 1974). Recently, several reports have suggested that cortical and hippocampal synaptic receptors are comprised of unique subunit combinations (Stocca and Vicini, 1998; Tovar and Westbrook, 1999). In particular, the NR2A subunit is inserted into synaptic receptor populations soon after activity begins in hippocampal neurons in culture (Tovar and Westbrook, 1999). By using patchclamp recordings from cerebellar slices combined with a selective NR1/NR2B receptor antagonist, we present evidence for NR2A subunit insertion at cerebellar mossy fiber-granule neuron synapses soon after activity begins. We also show that the extrasynaptic receptor population undergoes a similar, albeit much delayed, developmental change. 


\section{MATERIALS AND METHODS}

Electrophysiological recordings and slices preparation. Sagittal slices of cerebellum $(180-250 \mu \mathrm{m})$ were prepared from postnatal days 6-30 (P6-P30) Sprague Dawley rats, as described previously (Puia et al., 1994).

The recording chamber was continuously perfused at $5 \mathrm{ml} / \mathrm{min}$ with an oxygenated extracellular medium composed of: $120 \mathrm{mM} \mathrm{NaCl}, 3.1 \mathrm{~mm}$ $\mathrm{KCl}, 1 \mathrm{~mm} \mathrm{MgCl}, 1.25 \mathrm{~mm} \mathrm{~K}_{2} \mathrm{HPO}_{4}, 26 \mathrm{~mm} \mathrm{NaHCO}_{3}, 2.0 \mathrm{~mm} \mathrm{CaCl}{ }_{2}$, $1.25 \mathrm{~mm}$ glucose, and $10 \mu \mathrm{M} \mathrm{D}$-serine. The solution was maintained at $\mathrm{pH}$ 7.4 by bubbling with $5 \% \mathrm{CO}_{2}-95 \% \mathrm{O}_{2}$. NMDA receptor-mediated synaptic responses were pharmacologically isolated by picrotoxin $(15 \mu \mathrm{M}$; Sigma, St. Louis MO), strychnine (10 $\mu \mathrm{M}$; Sigma), and 2,3-dihydro-6nitro-7-sulfamoyl-benzo(F)quinoxaline (NBQX) $(5 \mu \mathrm{M}$; Tocris Cookson, Ballwin MO). (1S,2S)-1-(4-hydroxyphenyl)-2-(4-hydroxy-4-phenylpiperidino)-1-propanol (CP 101,606) (Chenard et al., 1995) was a gift from Dr. Richard Woodward (Acea Pharmaceutical, Irvine, CA). CP 101,606 and NBQX were dissolved in dimethylsulfoxide $(<0.1 \%$ final concentration). Spermine tetrahydrochloride (Sigma), (+)-MK-801 maleate (Dizocilpine; Tocris Cookson), and all other drugs were dissolved in water. All drugs were perfused through parallel inputs to the perfusion chamber.

Electrodes were pulled from borosilicate glass capillaries (Wiretrol II; Drummond, Broomall, PA). Nucleated patches and whole-cell recordings from cerebellar granule neurons were obtained under visual control with an Axioskop FS microscope (Zeiss, Oberkochen, Germany) equipped with Nomarski optics and an electrically insulated water immersion $40 \times$ objective with a long working distance. Typical pipette resistance was 6-8 $\mathrm{M} \Omega$. Intracellular (patch pipette) solutions contained (in $\mathrm{mM}$ ): K-gluconate 145, EGTA 5, $\mathrm{MgCl}_{2}$ 5, ATP-Na 5.0 GTP-Na 0.2, and HEPES 10, adjusted to $\mathrm{pH} 7.2$ with KOH. Whole-cell recordings were performed with a patch-clamp amplifier (Axopatch 200B; Axon Instruments, Foster City, CA). We discarded cells in which a change in series resistance greater than $15 \%$ was observed.

Evoked NMDA EPSCs were acquired by stimulation of the mossy fiber inputs located in the vicinity of the recorded granule cell. To evoke EPSCs, a tungsten bipolar electrode was placed on the white matter located near the recorded cell. Stimulus durations ranged from 50 to 100 $\mu \mathrm{sec}$, and stimulus intensity ranged from 200 to $300 \mu \mathrm{A}$. To isolate NMDA EPSCs, NBQX $(5 \mu \mathrm{M})$, strychnine $(20 \mu \mathrm{M})$, and picrotoxin $(15$ $\mu \mathrm{M})$ were perfused during the entire recording.

For fast application of L-glutamate, we used a computer-driven piezoelectric translator (PZ 150M; Burleigh Instruments, Fishers, NY) to which double-barrel theta tubing was attached. Nucleated outside-out membrane patches were excised from the neurons immediately after establishing the whole-cell configuration and positioned in front of the double-barrel applicator (Puia et al., 1994). In each barrel, we used extracellular medium containing $5 \mu \mathrm{M} \mathrm{NBQX}$ with and without $1 \mathrm{~mm}$ L-glutamate (flow rate of $0.25 \mathrm{ml} / \mathrm{min}$ ). After each recording, on and off rates, as well as pulse duration, were measured by "blowing off" the patch and recording currents generated by the liquid junction potential caused by a 50:1 dilution of the $\mathrm{L}$-glutamate-containing solution (Lester and Jahr, 1992). For fast application of L-glutamate in combination with other drugs, we rapidly exchanged the solutions in both barrels by means of solenoid valves connected to a vacuum. Drugs were added in both control and L-glutamate-containing solutions.

Data collection and analysis. Currents were filtered at $1 \mathrm{kHz}$ with an eight-pole low-pass Bessel filter (Frequency Devices, Haverhill, MA), digitized at $5-10 \mathrm{kHz}$ using an IBM-compatible microcomputer equipped with Digidata 1200 data acquisition board (Axon Instruments) and pClamp 8 software (Axon Instruments). Off-line data analysis, curve fitting, and figure preparation were performed with Clampfit 8 (Axon Instruments) and Origin 4.1 (Microcal, Northampton, MA) software. Fitting of the decay phase of currents recorded from excised patches and NMDA EPSCs was performed using a simplex algorithm for leastsquares exponential fitting routines. Decay times of averaged currents derived from fitting to double exponential equations of the form $I(t)=I_{\mathrm{f}}$ $* \exp \left(-t / \tau_{\mathrm{f}}\right)+I_{\mathrm{s}} * \exp \left(-t / \tau_{\mathrm{s}}\right)$, where $I_{\mathrm{f}}$ and $I_{\mathrm{s}}$ are the amplitudes of the fast and slow decay components, and $\tau_{\mathrm{f}}$ and $\tau_{\mathrm{s}}$ are their respective decay time constants used to fit the data. To compare decay times, we used a weighted mean decay time constant: $\tau_{\mathrm{w}}=\left[I_{\mathrm{f}} /\left(I_{\mathrm{f}}+I_{\mathrm{s}}\right)\right] * t_{\mathrm{f}}+\left[I_{\mathrm{s}} /\left(I_{\mathrm{f}}+I_{\mathrm{s}}\right)\right]$ $* t_{\mathrm{s}}$. Data values are expressed as mean \pm SEM, and $p$ values represent the results of paired or independent two-tailed $t$ tests (as indicated).

\section{RESULTS}

\section{Pharmacological and kinetic properties of synaptic NMDA receptors}

Cerebellar granule neurons were identified by their anatomical location in the granule layer and by their small cell bodies. After the formation of a gigaseal, cells were voltage clamped at $-60 \mathrm{mV}$ in the whole-cell recording configuration. After a short latency period during which the cell was allowed to stabilize, a stimulating electrode was placed on the mossy fibers, and EPSCs were evoked. NBQX, picrotoxin, and strychnine were included in $\mathrm{Mg}^{2+}$-free perfusion solution to pharmacologically isolate the NMDA component of the EPSC. To ensure that the resulting component of the EPSC was caused solely by the activation of NMDA receptors, the competitive NMDA antagonist ( \pm )-3-(2carboxy piperazin-4-yl)-propyl-1-phosphonic acid (CPP) was bath applied. In all cells tested, $10 \mu \mathrm{M}$ CPP completely and reversibly blocked the resulting evoked current ( $n=4$; data not shown). The decay time of NMDA EPSCs at all developmental stages was best fitted with a dual exponential function. To allow a more direct comparison among EPSC decay kinetics, we described the dual exponential decay using a weighted time constant $\left(\tau_{\mathrm{w}}\right)$.

To verify the change in decay kinetics during development, we analyzed NMDA EPSCs from rats ranging from 6 to $30 \mathrm{~d}$ old (Fig. $1 A$, Table 1). As reported previously, decay times from more mature animals exhibited much faster decay times (Takahashi et al., 1996). During the second postnatal week (P10-P14), NMDA current from granule neurons showed intermediate decay kinetics (Table 1), a time when mRNAs for NR2A, NR2B, and NR2C subunits are all present (Watanabe et al., 1994; Wang et al., 1995).

During the first postnatal week, when mossy fiber-granule cell synapses form (Arsenio Nunes and Sotelo, 1985), the primary NR2 subunit detected by Western blot analysis is NR2B (Takahashi et al., 1996). We were able to evoke NMDA EPSCs in the cerebellum as early as P6. Currents at this age yielded large weighted time constants and exceedingly long, slow tails (Fig. 1). NMDA EPSCs during this period (P6-P8) were partially blocked by $\mathrm{CP} 101,606(5 \mu \mathrm{M})$ (Fig. $1 B, C)$, an antagonist selective for NR1/NR2B heteromers (Mott et al., 1998) that has been shown to be devoid of presynaptic action in cortical neurons (Stocca and Vicini, 1998). However, the extent of blockade was never as strong as that observed with recombinant receptors (Mott et al., 1998). Evoked NMDA EPSCs from granule neurons in rats ranging from $\mathrm{P} 10$ to $\mathrm{P} 14$ showed greater variability in $\mathrm{CP} 101,606$ blockade $(5 \mu \mathrm{M})$ (Fig. $1 B, C)$. This greater variability of blockade together with a decrease in decay times (Fig. $1 C$, Table 1) parallels the reported increase of NR2A subunit expression in this age group (Watanabe et al., 1994). A nonsynchronized developmental expression of the NR2A receptor subunit between different cells as reported for NR2C subunit (Ozaki et al., 1997) could underlie the large variability of CP101,606 effect in Figure $1 B$.

\section{NMDA responses in excised nucleated patches}

To make a direct comparison of synaptic to extrasynaptic receptors, we chose to study nucleated outside-out patches (Puia et al., 1994). These patches have a greater surface area than conventional outside-out patches and therefore a greater number of NMDA receptors. This allowed for a reliable measure of deactivation kinetics from a smaller number of repetitive L-glutamate applications. Deactivation of nucleated patch responses was best described by double exponential curves with similar time constants to those measured for NMDA EPSCs (Table 1). However, 


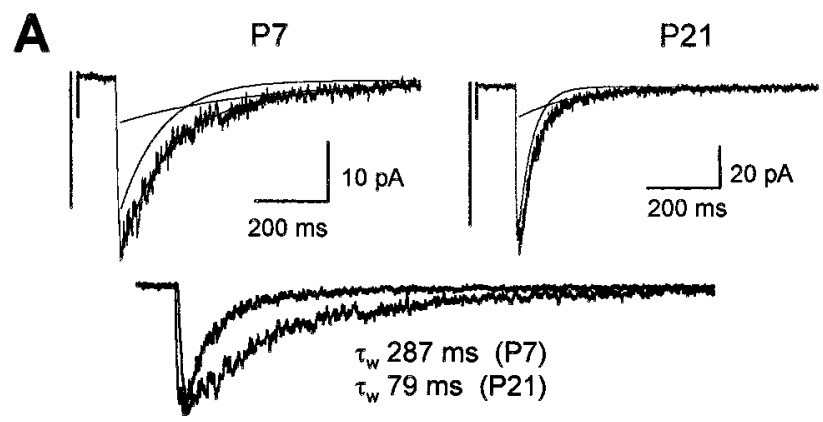

B
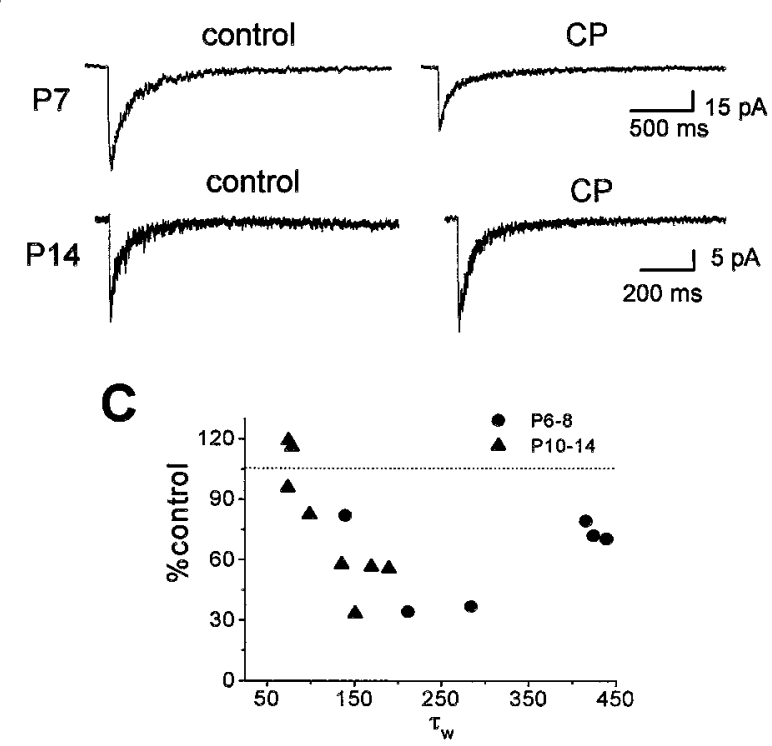

Figure 1. Comparison of kinetic and pharmacological properties of evoked NMDA EPSCs in developing granule neurons. A, Top, Evoked NMDA EPSCs from granule neurons in rats at P7 and P21. The averages of 5-10 consecutive sweeps are shown with a superimposed double exponential curve. The individual exponential curves are also shown. Bottom, The two responses are shown superimposed after scaling with an indication of the weighted time constant $\left(\tau_{\mathrm{w}}\right)$ to emphasize differences in deactivation. $B$, Top, Average of five to seven traces taken from a P7 rat before (control) and in the presence of $5 \mu \mathrm{M} \mathrm{CP} 101,606(C P)$. Bottom, Average of six to seven traces taken from a P14 rat before (control) and in the presence of $5 \mu \mathrm{M} \mathrm{CP} 101,606(C P)$. C, Relationship between percentage control response in the presence of CP 101,606 $(5 \mu \mathrm{M})$ as a function of the weighted time constant of NMDA EPSCs in P6-P8 and P10-P14 rats.

patch responses had on average larger peak amplitudes than NMDA EPSCs (Table 1).

Occasionally, responses from nucleated patches were quite small. This allowed us to observe the behavior of a few NMDA channels during the tail of patch responses (Fig. 2A). Channel behavior was strikingly different when comparing responses from younger (P7-P8) with older [greater than P18 (P>18)] animals. Patch responses from immature neurons resulted in channel bursting many hundreds of milliseconds after glutamate application, whereas responses in older animals had noticeably fewer openings during the same time period. As seen for NMDA EPSCs, decay times of average responses in nucleated patches also decreased with age (Fig. $2 B$, Table 1). In nucleated patches from animals further along in development $(\mathrm{P}>18)$, glutamate activated currents decayed faster when compared with immature neurons (P6-P8) (Fig. 2C). Weighted time constants of deactivation from responses in nucleated patches were significantly faster with development but were not significantly different from NMDA EPSCs in rats at P7-P8 (Table1). In mature animals $(\mathrm{P}>18)$, the weighted time constants from patch responses were not significantly different from NMDA EPSCs despite the presence of two uncharacteristically slow responses (Fig. 2C). The average weighted time constants of patch responses were virtually identical to NMDA EPSCs when these two patches were excluded from the older group. Weighted time constants of patch responses from animals in the P10-P14 age group had intermediate values and were significantly different from NMDA EPSCs in the same age group (Table 1).

\section{Pharmacological antagonism of nucleated patch responses}

Our findings suggest that extrasynaptic NMDA receptors undergo similar kinetic changes throughout development when compared with synaptic receptors. Therefore, it was reasonable to assume that sensitivity of glutamate responses in nucleated patches to NR2B-specific antagonists could be similar to NMDA EPSCs from the same developmental period. We investigated the effect of $5 \mu \mathrm{M} \mathrm{CP} 101,606$ on L-glutamate responses in excised nucleated patches from cerebellar granule neurons from rats in the three age groups. Efficacy of CP 101,606 blockade was tested on $200 \mathrm{msec}$ applications of L-glutamate to excised nucleated patches.

Contrary to NMDA EPSCs, patch responses were highly sensitive to application of the NR1/NR2B antagonist. Application of CP 101,606 to nucleated patches in rats at P6-P8 resulted in an almost complete abolishment of peak NMDA current in all cells tested $(n=6)$ (Fig. 3A,C). Likewise, in patches from P10-P14 rats $(n=7)$, CP 101,606 also blocked peak NMDA current efficaciously (Fig. 3). CP 101,606 was less efficacious in $\mathrm{P}>18$ rats $(n=6)$ (Fig. $3 B, C)$. As reported previously (Stocca and Vicini, 1998), only a partial recovery from NR2B-specific antagonists was observed (Fig. $3 A$ ). Figure $3 C$ demonstrates the relationship between the weighted time constant of patch responses and the magnitude of block by the NR1/NR2B antagonist. In these experiments, patch currents were elicited by $4 \mathrm{msec}$ glutamate pulses to assess deactivation. CP 101,606 was less effective on patch responses with exceedingly fast weighted time constants $\left(\tau_{\mathrm{w}}\right.$ $<100 \mathrm{msec}$ ), indicating a possible correlation with NR2A subunit expression (Fig. $3 C$ ).

We also directly compared the average blockade of patch responses by $5 \mu \mathrm{M} \mathrm{CP}$ 101,606 with average blockade of NMDA EPSCs (Fig. 3B). The effect of CP 101,606 on NMDA EPSC amplitude was lost in some neurons as early as P10, and it was not significant in the P10-P14 age group (Fig. 3B). In contrast, the effect of the NR2B antagonist on patch responses in this age group was not different from that in the P6-P8 age group. Even for NMDA EPSCs in rats at P6-P8, when decay kinetics are at their slowest (Table 1), the CP 101,606 blockade was significantly less than patch responses of the same age (Fig. 3B). Although the antagonist had no significant effect on the $\mathrm{P}>18$ age group as a whole, CP 101,606 sensitivity was still observed in some patches as late as P30 (Fig. 3C).

Patch excision has been found to alter properties of NMDA receptor channels (Lester and Jahr, 1992; Clark et al., 1997). Clark et al. (1997) have shown that excising patches from granule neurons alters the conductance of extrasynaptic NMDA receptors. However, we did not observed changes in channel current amplitude in nucleated patches. At a holding potential of -60 $\mathrm{mV}$, NMDA channel current amplitude was $4.1 \pm 0.1 \mathrm{pA}$ in 
Table 1. Characteristics of NMDA currents recorded in developing granule neurons in rat cerebellar slices

\begin{tabular}{|c|c|c|c|c|c|c|c|}
\hline & & $\begin{array}{l}\text { Amplitude } \\
(\mathrm{pA})\end{array}$ & $\tau_{\mathrm{W}}(\mathrm{msec})$ & $\tau_{\text {fast }}(\mathrm{msec})$ & $\tau_{\text {slow }}(\mathrm{msec})$ & $\%$ Fast & $n$ \\
\hline \multirow[t]{2}{*}{ P6-P8 } & EPSC & $65 \pm 5$ & $320 \pm 59$ & $154 \pm 19$ & $726 \pm 137$ & $65 \pm 5$ & 9 \\
\hline & PATCH & $123 \pm 24^{*}$ & $311 \pm 39$ & $125 \pm 17$ & $1370 \pm 136$ & $85 \pm 2$ & 10 \\
\hline \multirow[t]{2}{*}{ P10-P14 } & EPSC & $35 \pm 5 \dagger$ & $129 \pm 10 \dagger$ & $48 \pm 4 \dagger$ & $264 \pm 21 \dagger$ & $62 \pm 3$ & 23 \\
\hline & PATCH & $94 \pm 22^{*}$ & $174 \pm 12^{*} \dagger$ & $70 \pm 5^{*} \dagger$ & $634 \pm 76^{*}$ & $75 \pm 2$ & 25 \\
\hline \multirow[t]{2}{*}{$\mathrm{P}>18$} & EPSC & $36 \pm 5 \dagger$ & $86 \pm 11 \dagger$ & $67 \pm 17 \dagger$ & $283 \pm 68 \dagger$ & $74 \pm 4$ & 4 \\
\hline & PATCH & $98 \pm 20^{*}$ & $129 \pm 30 \dagger$ & $67 \pm 15 \dagger$ & $497 \pm 137 \dagger$ & $81 \pm 3$ & 14 \\
\hline
\end{tabular}

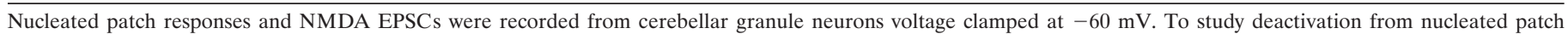

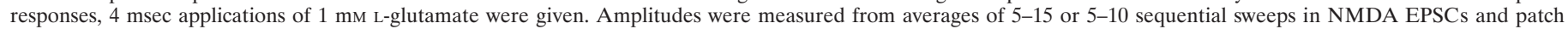

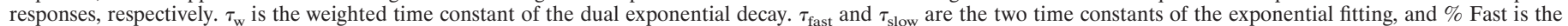

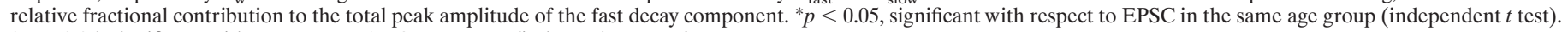
$t p<0.05$, significant with respect to P6-P8 age group (independent $t$ test).

nucleated patches $(n=7)$ and $4.0 \pm 0.1 \mathrm{pA}$ in the whole-cell configuration $(n=15)$. This does not exclude the possibility that nucleated patch excision does not alter other channel properties.

\section{CP 101,606 blocks extrasynaptic NMDA receptors after MK-801 blockade of NMDA EPSCs}

One of the most valuable characteristics of the high signal-tonoise ratio of recordings in cerebellar granule neurons is the ability to observe channel current activity in the whole-cell recording configuration (Silver et al., 1992). As soon as whole-cell recordings were established in the presence of bicuculline and NBQX, spontaneous NMDA channel currents (Fig. 4A) were observed in all cells recorded $(n=15)$, as investigated previously in detail by Rossi and Slater (1993). The extent of spontaneous activity was variable from cell to cell and was abolished by $10 \mu \mathrm{M}$ CPP in all cells tested $(n=4)$. CP 101,606 (5 $\mu \mathrm{M})$, which had little effect on NMDA EPSCs at P14, had no obvious effect on spontaneous NMDA channels in the same age group (Fig. $4 A$ ). The average integral current in one second $\left(I_{\mathrm{i}}\right)$ was $645 \pm 73 \mathrm{pA}^{*} \mathrm{msec}$ in the absence and $661 \pm 82 \mathrm{pA}^{*} \mathrm{msec}$ in the presence of $\mathrm{CP}$ $101,606(n=5)$. However, in three of these neurons, perfusion of $10 \mu \mathrm{M}$ CPP resulted in blockade of spontaneous NMDA channel currents $\left(I_{\mathrm{i}}=109 \pm 45 \mathrm{pA}^{*} \mathrm{msec}\right)$.

The lack of effect of CP 101,606 on background NMDA channel activity and on NMDA EPSCs may relate to the lack of access in the brain slice rather than distinct receptor populations. Therefore, we attempted to block extrasynaptic NMDA receptors in the slice while recording in the whole-cell configuration from a P14 rat. To specifically block synaptic NMDA receptors, the open channel blocker MK-801 (10 $\mu \mathrm{M})$ was perfused until NMDA EPSCs were abolished (Fig. 4B). In this condition, receptors activated by bath perfusion of NMDA should be primarily extrasynaptic in origin. Indeed, as illustrated in Figure $4 C$, when 100 $\mu \mathrm{M}$ NMDA was perfused over the entire slice, a small population of receptors were activated $\left(I_{\mathrm{i}}=702 \pm 140 \mathrm{pA}^{*} \mathrm{msec}\right)$. This population of receptors was blocked when $5 \mu \mathrm{M} \mathrm{CP} 101,606$ was added to the NMDA solution $\left(I_{\mathrm{i}}=119 \pm 47 \mathrm{pA}^{*} \mathrm{msec} ; n=3\right)$.

\section{Spermine potentiates patch responses but not NMDA EPSCs}

Previous reports indicate that polyamines have the ability to potentiate recombinant NMDA receptors comprising NR2B subunits while producing no potentiation in recombinant NMDA receptors comprising NR2A subunits (Williams et al., 1994). To further investigate the apparent differences in subunit composition between synaptic and extrasynaptic NMDA receptors in cerebellar granule neurons, we applied spermine to both NMDA EPSCs and nucleated patch responses.

Spermine $(500 \mu \mathrm{M})$ was ineffective in potentiating the peak of NMDA EPSCs in P6-P8 granule neurons (Fig. 5A, $C$ ). In five of six cells tested, bath perfusion of spermine either had no effect or slightly reduced the peak of NMDA EPSCs from animals in this age group. As for CP 101,606, we were concerned that spermine was not able to access synaptic NMDA receptors. Therefore, we analyzed single-channel currents from the tails of evoked NMDA responses before and after bath perfusion of spermine (Fig. 5A). At a holding potential of $-60 \mathrm{mV}$, channel currents were $4.1 \pm$ $0.1 \mathrm{pA}$ in control and $2.2 \pm 0.3 \mathrm{pA}$ when spermine was present $(n=4)$, consistent with previous reports (Rock and MacDonald, 1992). When spermine $(500 \mu \mathrm{M})$ was applied to nucleated patches from P10-P14 animals, we observed quite different effects when compared with P7 NMDA EPSCs (Fig. 5), although it also reduced NMDA single-channel current amplitude (data not shown). In seven of eight cells tested, spermine potentiated peak NMDA current from patch responses in animals through the second postnatal week (Fig. $5 B, C$ ).

\section{DISCUSSION}

Decay times of NMDA EPSC in rat cerebellar granule neurons decrease during the first 3 weeks after birth, as reported previously (Feldemeyer and Cull-Candy, 1996; Takahashi et al., 1996). In parallel, we report similar kinetic changes for deactivation of L-glutamate responses in nucleated patches excised from these neurons. In contrast to NMDA EPSCs, nucleated patch responses remained sensitive to an NR1/NR2B-specific antagonist for a much longer period during development. In addition, spermine, which potentiated patch currents from rats through the second postnatal week, had no effect on NMDA EPSCs, even at early stages of development.

\section{NR2A subunit targeted to synaptic receptors in granule neurons}

Recent studies suggest the incorporation of the NR2A subunit into synaptic receptors in hippocampal and cortical neurons (Li et al., 1998; Stocca and Vicini, 1998; Tovar and Westbrook, 1999). We extend these findings to cerebellar granule neurons by suggesting that the NR2A subunit is inserted into the synaptic receptor population at a time when synaptogenesis and synaptic activity begins. Functional mossy fiber-granule neuron synapses have been reported as early as P5 (Takahashi et al., 1996), as confirmed by anatomical data (Arsenio Nunes and Sotelo, 1985). At this early age, mRNA and protein studies indicate that the 

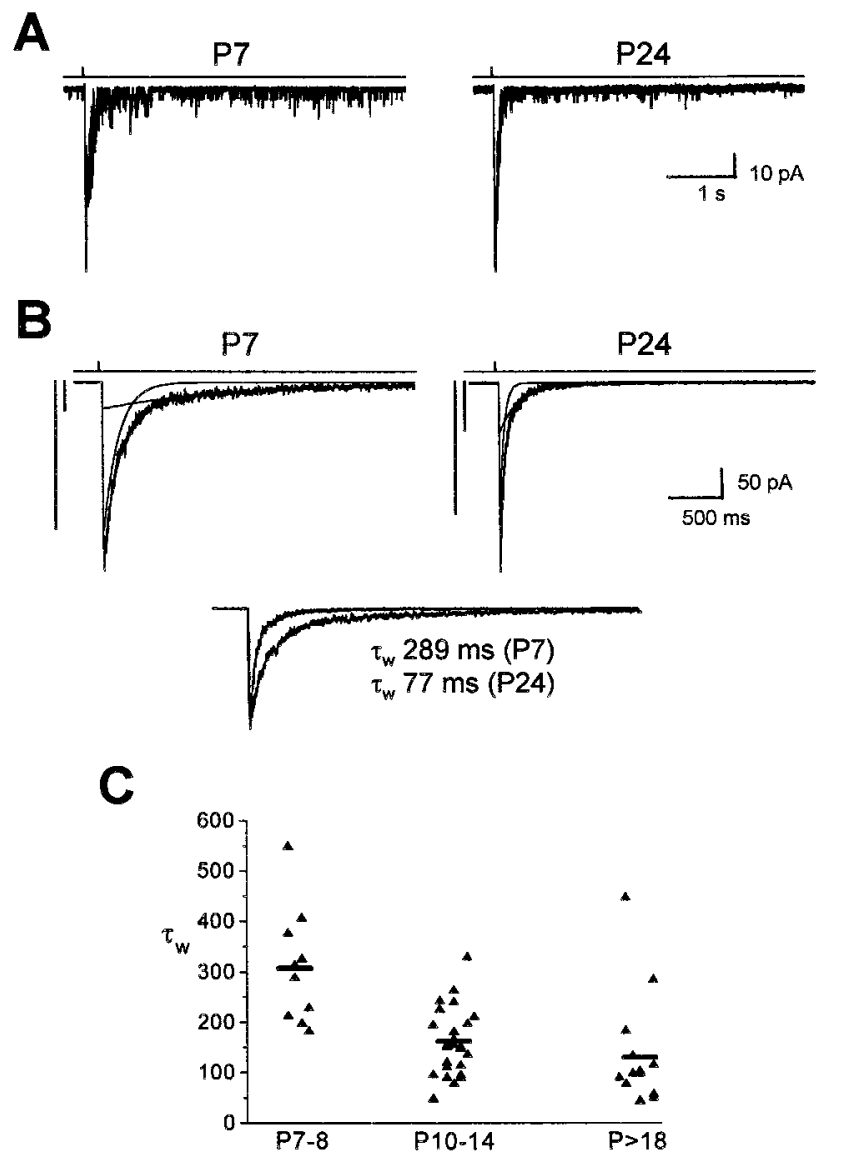

Figure 2. Deactivation of patch responses accelerate with development. $A$, Single response to L-glutamate $(1 \mathrm{mM}, 4 \mathrm{msec})$ in nucleated patches from P7 and P24 rats. B, Top, Average L-glutamate $(1 \mathrm{~mm}, 4 \mathrm{msec})$ activated currents in two nucleated patches from P7 and P24 rats. The average of seven consecutive L-glutamate applications are shown with a superimposed double exponential curve. The individual exponential curves are also shown. Bottom, The two responses are shown overlapped after scaling with an indication of the weighted time constant $\left(\tau_{\mathrm{w}}\right)$ to emphasize differences in deactivation. $C$, Summary of all individual weighted time constants from NMDA responses in nucleated patches at three developmental age groups (P7-P8, P10-P14, and greater than P18). Horizontal bar located among responses indicates arithmetic mean.

NR2B subunit is much more abundant than the NR2A subunit (Akazawa et al., 1994; Wang et al., 1995; Takahashi et al., 1996). However, we found that NMDA EPSCs in these young rats were poorly sensitive to $\mathrm{CP} 101,606$, indicating the contribution of NR2A subunits to synaptic NMDA receptors. The report that synaptic receptors are of uniform high conductance $(59 \mathrm{pS})$ in rats at P12-P13 (Clark et al., 1997) suggests the absence of the NR2C subunit early in development. Furthermore, CP 101,606 sensitivity in newly formed synapses was much different from patch responses in animals of the same age. Additionally, through the second postnatal week, sensitivity to the NR2B blocker was lost for synaptic receptors but changed only slightly in patch responses. It is only later in development that extrasynaptic receptors exhibit waning sensitivity to the antagonist.

\section{NR2B subunit is slow in disappearing from cell bodies} during development

The extent of current blockade by CP 101,606 was indistinguishable between recombinant NR1/NR2B receptors (Mott et al., 1998) and NMDA receptors in the cell body of granule neurons

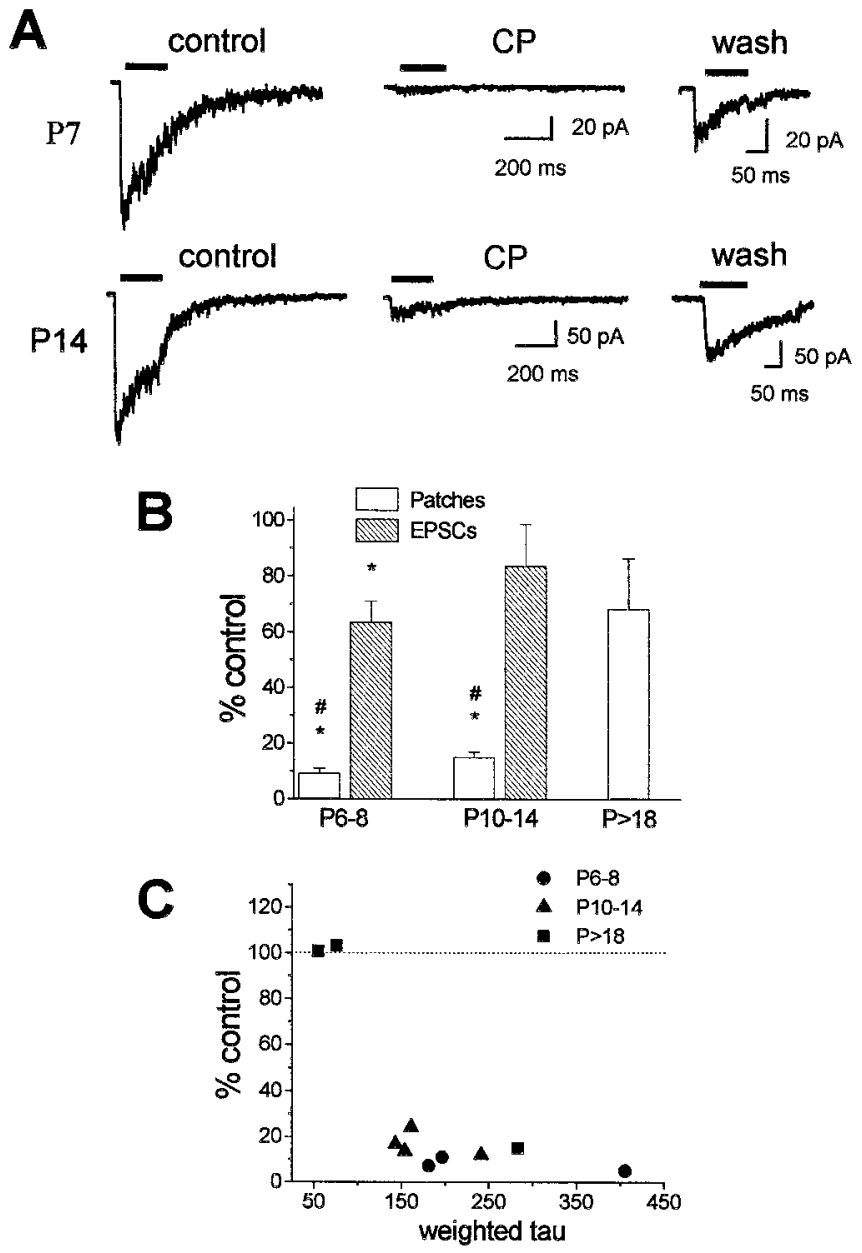

Figure 3. Effect of NR1/NR2B antagonists on nucleated patch responses. $A$, Top, Responses to $1 \mathrm{mM}$ L-glutamate before (control), during $(C P)$, and after (wash) application of $5 \mu \mathrm{M} \mathrm{CP} 101,606$ in a P7 rat. In each panel, at least four traces were averaged. Bottom, As above, with responses elicited from nucleated patches in a P14 rat. In both panels, horizontal bars indicate duration of L-glutamate applications $(200 \mathrm{msec})$. $B$, A comparison of the effect of NR1/NR2B-specific antagonists between patch responses and NMDA EPSCs of the same age. ${ }^{*} p<0.05$, significant differences from $100 \%$ (independent $t$ test); $\# p<0.01$, statistical significance between nucleated patches and NMDA EPSCs of the same age group (independent $t$ test). $C$, The relationship between the percentage control after CP 101,606 application and the weighted time constant of nucleated patch responses ( $4 \mathrm{msec}$ pulses) from rats in the three age groups.

in slices from rats during the first 2 postnatal weeks. Furthermore, we observed NMDA responses from nucleated patches that were sensitive to $\mathrm{CP} 101,606$ in older rats $(\mathrm{P}>18)$. At the same time, however, in this group the majority of patches were insensitive to NR1/NR2B antagonists. Together, these results indicate that, as the NR2B subunit disappears from granule neurons, NMDA responses in both extrasynaptic and synaptic populations are produced by receptors composed of subunits other than NR2B. This is further supported by the presence of low conductance channels in patches excised from granule cell bodies in wild-type and NRA knock-out mice after the second postnatal week, indicating the presence of the NR2C subunit (Takahashi et al., 1996).

Compared with synaptic receptors, the insertion of subunits other than NR2B in receptors located on cell body of granule neurons occurs with a delay. This is apparent after seeing the 



$8 \mathrm{pA}$

$2 s$

Figure 4. CP 101,606 blockade of extrasynaptic receptors in the intact granule neuron. $A$, Top, Spontaneous NMDA channel currents recorded after establishing a whole-cell recording from a P14 rat. Middle, Effect of bath perfusion of $5 \mu \mathrm{M}$ CP 101,606. Bottom, Trace represents effect of 10 $\mu \mathrm{M}$ CPP on spontaneous NMDA single channel events. CPP was bath applied immediately after CP 101,606. B, Evoked NMDA EPSCs in the presence of $10 \mu \mathrm{M}$ MK-801 recorded in the same cell after washout of CPP. Stimulus frequency was $0.1 \mathrm{~Hz}$. Responses at different stimulus number (Stim) from the beginning of MK-801 perfusion are illustrated. $C$, Top, Current sweep taken immediately after Stim 30 in B. MK-801 was allowed to wash for $\sim 3 \mathrm{~min}$. Middle, Bath perfusion of $100 \mu \mathrm{M}$ NMDA after MK-801 wash. Bottom, Trace acquired 2 min after application of a solution containing both $100 \mu \mathrm{M}$ NMDA and $5 \mu \mathrm{M} \mathrm{CP} 101,606$.

differences in CP 101,606 sensitivity between extrasynaptic and synaptic receptors among all groups tested. For instance, CP 101,606 sensitivity of individual neurons from evoked NMDA EPSCs from P10-P14 rats is similar to individual responses from nucleated patches in animals older than P18. Some responses were reduced, whereas others exhibited no reduction or slight potentiation. These results are further supported by the fact that CP 101,606 blocks NMDA receptors in the intact granule neurons after synaptic receptors were inhibited by MK-801 from P14 rats. Spermine, which selectively potentiates peak NMDA current from recombinant NR1a/NR2B receptors, did not increase current amplitude in NR1a/NR2A receptors (Williams et al., 1994). Spermine potentiated patch responses from P14 rats but was ineffective in potentiating the peak of NMDA EPSCs at P7. These data further support the hypothesis that NR2B is slow in disappearing from granule cell bodies during development.
A
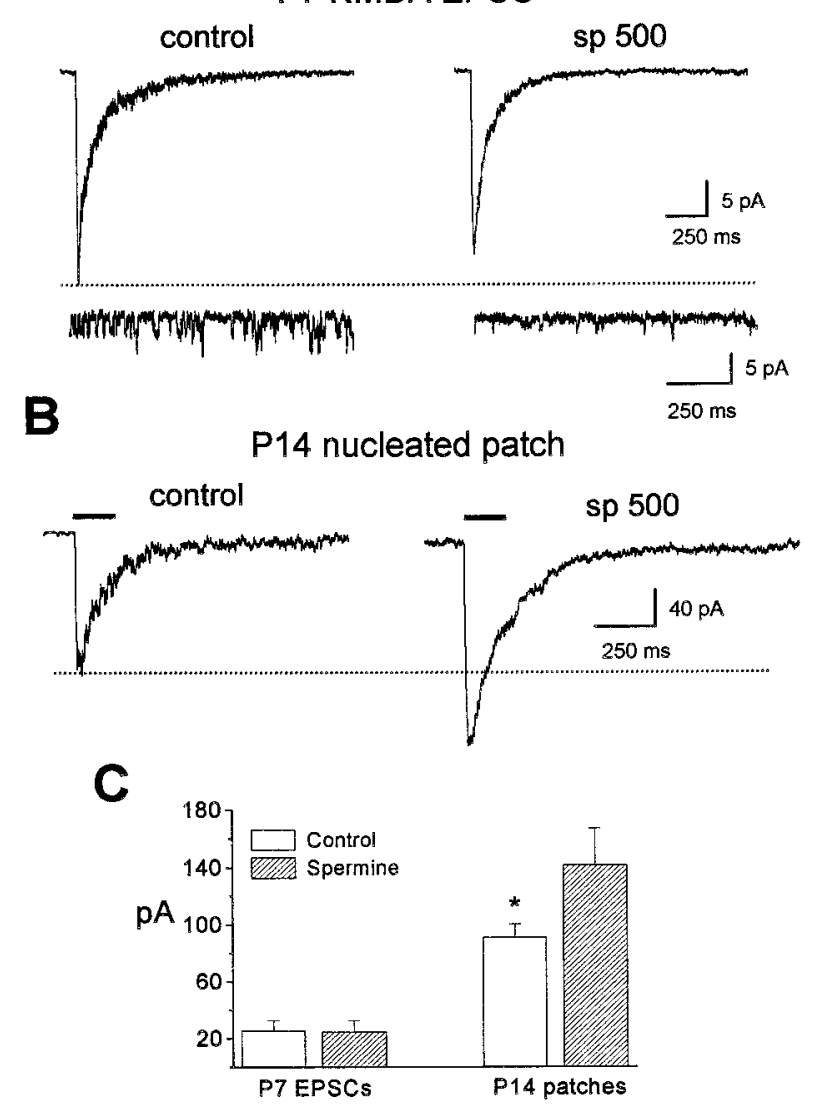

Figure 5. Spermine potentiates patch responses but not NMDA EPSCs. $A$, Top, Evoked NMDA EPSCs from a P7 granule neuron. Left trace represents average of 20 consecutive sweeps in control conditions. Right trace represents the average of 15 sweeps in the presence of $500 \mu \mathrm{M}$ spermine (sp 500). Bottom, Left trace represents single-channel currents from the tail of individual evoked NMDA EPSCs in control conditions. Right trace represents NMDA single-channel currents from the same cell in the presence of $500 \mu \mathrm{M}$ spermine. In both traces, overlapped channel openings were observed. $B$, Nucleated patch responses from a P14 granule neuron. Left trace is the average of five consecutive $200 \mathrm{msec}$ L-glutamate applications in control conditions. Right trace is the average of five consecutive $200 \mathrm{msec}$ L-glutamate applications in the presence of $500 \mu \mathrm{M}$ spermine (sp 500). Horizontal bars indicate duration of the L-glutamate applications. $C$, Summary illustrating peak NMDA EPSCs in rats at P7 $(n=6$ cells $)$ and peak patch currents in P14 rats $(n=8$ cells $)$ in the absence and the presence of $500 \mu \mathrm{M}$ spermine. ${ }^{*} p<0.05$, statistical significance between control and spermine responses (paired $t$ test).

Our results with spermine as a marker for the NR2B subunit have to be taken with caution. It is possible that spermine may not efficaciously increase the peak of synaptic NMDA responses because of inherent differences between synaptic and extrasynaptic receptors other than just latency of NR2A subunit expression and NR2B disappearance. One possibility is that synaptic NMDA receptors contain NR1 splice variants with exon 5. It has been shown that recombinant NR2B receptor sensitivity to spermine is abolished when coexpressed with the NR1b splice form (Durand et al., 1992). Also, we cannot rule out the effect of spermine on presynaptic voltage-gated calcium channels or other processes involved in synaptic transmission. Lastly, the effect of spermine on channel conductance complicates the interpretation of the effects on peak current. 


\section{Alternative interpretations of distinct effects of drugs in synaptic and extrasynaptic receptors}

The fact that mossy fiber-granule neuron synapses are enclosed in the glomerulus and the inherent thickness of the slice may have hindered the effective access of drugs to synaptic receptors. Experiments with CPP and spermine argue against this possibility. CPP quickly and efficaciously blocked synaptic NMDA receptors in all cells tested. Moreover, we were able to determine the presence of spermine in the synapse by its effect on the channel current amplitude observed in the tail of NMDA EPSCs. Lastly, experiments with MK-801 showed that CP 101,606 is indeed able to penetrate the tissue and inhibit extrasynaptic NMDA receptors during whole-cell recordings in the slice.

A second concern is for artifactual alterations of CP 101,606 sensitivity. Patch excision as the reason for increased CP 101606 sensitivity of extrasynaptic receptors seems unlikely because it was also observed during whole-cell recordings. Furthermore, some patch responses were insensitive to this drug in mature rats.

\section{Consequences for deactivation from changes in subunit composition during development}

There is clear evidence for distinct decay kinetics among recombinant receptors containing NR1 and NR2 subunits, with NR1/ NR2A heteromers being the fastest (Monyer et al., 1994; Vicini et al., 1998). Native receptors in the cerebellum also seem to have similar characteristics. Experiments with NR2C knock-out mice show that, in P14-P18 animals, NMDA EPSCs are faster when compared with their wild-type counterparts (Ebralidze et al., 1996). Furthermore, NMDA EPSC decay times from NR2C knock-out mice (Ebralidze et al., 1996) correlate closely to deactivation kinetics measured from recombinant NR1/NR2A receptors (Vicini et al., 1998). In this work, we confirm the decrease in NMDA EPSC decay times during development. Early in development, when synapses first form, NMDA EPSCs are at their slowest. This is suggestive of a high proportion of receptors containing NR2B. However, as development proceeds, decay times for EPSCs decrease. This is suggestive of the disappearance of the NR2B subunit and the increased expression of the NR2A subunit in synaptic populations. This phenomenon parallels a gradual decrease in CP 101,606 sensitivity.

In extrasynaptic populations, CP 101,606 sensitivity of patch responses does not significantly change during the first 2 weeks, but deactivation is significantly faster during the second postnatal week. This result indicates that deactivation of NMDA responses may not exclusively be determined by the changes in expression of NR2 subunits. Other factors may also influence deactivation kinetics. For example, evidence from NR2A knock-out mice show that NMDA EPSC decay times still increase with age (Takahashi et al., 1996), although recombinant NMDA receptor data show little differences between NR1/NR2B and NR1/ NR2C current deactivation (Monyer et al., 1994; Vicini et al., 1998). Also, although our data show that the reported decrease in channel conductance in excised patches (Clark et al., 1997) does not occur in nucleated patches, we cannot rule out that, during development, patch excision may artificially accelerate deactivation kinetics.

Our work suggests that receptors primarily comprised of the NR2B subunit can display relatively fast decay times yet still possess characteristics of NR1/NR2B receptors, such as $\mathrm{CP}$ 101,606 and spermine sensitivity. At the same time, slow NMDA EPSCs in immature rats display a decreased sensitivity to NR2B antagonists (Stocca and Vicini, 1998; Tovar and Westbrook,
1999). Further studies will be necessary to clarify whether the presumed formation of receptors containing more than one type of NR2 subunit may underlie some of these findings (Vicini et al., 1998).

\section{Conclusions}

Our results further support the hypothesis that NMDA receptors containing the NR2A subunit can rapidly integrate into synapses around the time of synaptogenesis (Tovar and Westbrook, 1999). However, we also provide clear evidence for the targeting of the NR2A subunit to extrasynaptic receptors later in development. What is the significance of this phenomenon? One possibility is that the presence of the NR2A subunit confers specific properties to extrasynaptic receptors, such as an increase in calciumdependent inactivation (Krupp et al., 1996) or a decrease in glutamate and glycine sensitivity (Laurie and Seeburg, 1994). In addition, NR1/NR2A heteromers with fast deactivation have limited ability to undergo persistent channel openings. This could result in an extrasynaptic receptor population that is more suitable for physiological activation only during intense neuronal activity.

\section{REFERENCES}

Akazawa C, Shigemoto R, Bessho Y, Nakanishi S, Mizuno N (1994) Differential expression of five $N$-methyl-D-aspartate receptor subunit mRNAs in the cerebellum of developing and adult rats. J Comp Neurol 347:150-160.

Arsenio Nunes ML, Sotelo C (1985) Development of the spinocerebellar system in the postnatal rat. J Comp Neurol 237:291-306.

Chenard BL, Bordner J, Butler TW, Chambers LK, Collins MA, De Costa DL, Ducat MF, Dumont ML, Fox CB, Mena EE, Menniti FS, Nielsen J, Pagnozzi MJ, Richter KEG, Ronau RT, Shalaby IA, Stemple JZ, White WF (1995) (1S,2S)-1-(4-hydroxyphenyl)-2-(4-hydroxy-4phenylpiperidino)-1-pr-opanol: a potent new neuroprotectant which blocks $N$-methyl-D-aspartate responses. J Med Chem 38:3138-3145.

Clark BA, Farrant M, Cull-Candy SG (1997) A direct comparison of the single-channel properties of synaptic and extrasynaptic NMDA receptors. J Neurosci 17:107-116.

Dingledine R, Borges K, Bowie D, Traynelis SF (1999) The glutamate receptor ion channels. Pharmacol Rev 51:7-61.

Durand GM, Gregor P, Zheng X, Bennett MV, Uhl GR, Zukin RS (1992) Cloning of an apparent splice variant of the rat $N$-methyl-Daspartate receptor NMDAR1 with altered sensitivity to polyamines and activators of protein kinase C. Proc Natl Acad Sci USA 89:9359-9365.

Ebralidze AK, Rossi DJ, Tonegawa S, Slater NT (1996) Modification of NMDA receptor channels and synaptic transmission by targeted disruption of the NR2C gene. J Neurosci 16:5014-5025.

Feldmeyer D, Cull-Candy S (1996) Functional consequences of changes in NMDA receptor subunit expression during development. J Neurocytol 25:857-867.

Kadotani H, Hirano T, Masugi M, Nakamura K, Nakao K, Katsuki M, Nakanishi S (1996) Motor discoordination results from combined gene disruption of the NMDA receptor NR2A and NR2C subunits, but not from single disruption of the NR2A or NR2C subunit. J Neurosci 16:7859-7867.

Krupp JJ, Vissel B, Heinemann SF, Westbrook GL (1996) Calciumdependent inactivation of recombinant NMDA receptors is NR2subunit specific. Mol Pharmacol 50:1680-1688.

Laurie DJ, Seeburg PH (1994) Ligand affinities at recombinant $N$-methyl-D-aspartate receptors depends on subunit composition. Eur J Pharmacol 268:335-345.

Lester RA, Jahr CE (1992) NMDA channel behavior depends on agonist affinity. J Neurosci 12:635-643.

Li JH, Wang YH, Wolfe BB, Krueger KE, Corsi L, Stocca G, Vicini S (1998) Developmental changes in localization of NMDA receptor subunits in primary culture of cortical neurons. Eur J Neurosci 10:1704-1715.

McBain CJ, Mayer ML (1994) N-Methyl-D-aspartic acid receptor structure and function. Physiol Rev 74:723-760.

Monyer H, Burnashev H, Laurie DJ, Sakmann B, Seeburg PH (1994) 
Developmental and regional expression in the rat brain and functional properties of the four NMDA receptors. Neuron 12:529-540.

Mott DD, Doherty JJ, Zhang S, Washburn MS, Fendley MJ, Lyuboslavsky P, Traynelis SF, Dingledine R (1998) Phenylethanolamines inhibit NMDA receptors by enhancing protein inhibition. Nat Neurosci 8:659-667.

Ozaki M, Sasner M, Yano R, Lu HS, Buonanno A (1997) Neuregulinbeta induces expression of an NMDA-receptor subunit. Nature 390:691-694.

Palay SL, Chan-Palay V (1974) Cerebellar cortex: cytology and organization. In: The mossy fibers, pp 142-179. New York: Springer.

Puia G, Costa E, Vicini S (1994) Functional diversity of GABAactivated $\mathrm{Cl}-$ currents in Purkinje versus granule neurons in rat cerebellar slices. Neuron 12:117-126.

Rock DM, MacDonald RL (1992) Spermine and related polyamines produce a voltage-dependent reduction of $N$-methyl-D-aspartate receptor single-channel conductance. Mol Pharmacol 42:157-164.

Rossi DJ, Slater NT (1993) The developmental onset of NMDA receptor-channel activity during neuronal migration. Neuropharmacology 32:1239-1248.

Sheetz AJ, Constantine-Paton M (1994) Modulation of NMDA receptor function: implication for vertebrate neural development. FASEB J 8:745-752.

Silver RA, Traynelis SF, Cull-Candy SG (1992) Rapid-time-course miniature and evoked excitatory currents at cerebellar synapses in situ. Nature 355:163-166.
Stocca G, Vicini S (1998) Increased contribution of NR2A subunit to synaptic NMDA receptors in developing rat cortical neurons. J Physiol 507:13-24.

Takahashi T, Feldmeyer D, Suzuki N, Onodera K, Cull-Candy SG, Sakimura K, Mishina M (1996) Functional correlation of NMDA receptor epsilon subunits expression with the properties of singlechannel and synaptic currents in the developing cerebellum. J Neurosci $16: 4376-4382$.

Tovar KR, Westbrook GL (1999) The incorporation of NMDA receptors with a distinct subunit composition at nascent hippocampal synapses in vitro. J Neurosci 19:4180-4188.

Vicini S, Wang JF, Li JH, Zhu WJ, Wang YH, Luo JH, Wolfe BB, Grayson DR (1998) Functional and pharmacological differences between recombinant NMDA receptors. J Neurophysiol 79:555-566.

Wang YH, Bosy TZ, Yasuda RP, Grayson DR, Vicini S, Pizzorusso T, Wolfe BB (1995) Characterization of NMDA receptor subunitspecific antibodies: distribution of NR2A and NR2B receptor subunits in rat brain and ontogenetic profile in the cerebellum. $\mathbf{J}$ Neurochem 65:176-183.

Watanabe M, Mishina M, Inoue Y (1994) Distinct spatiotemporal expressions of five NMDA receptor channel subunit mRNAs in the cerebellum. J Comp Neurol 343:513-551.

Williams K, Zappia AM, Pritchett DB, Shen YM, Molinoff PB (1994) Sensitivity of the $N$-methyl-D-aspartate receptor to polyamines is controlled by NR2 subunits. Mol Pharmacol 45:803-809. 